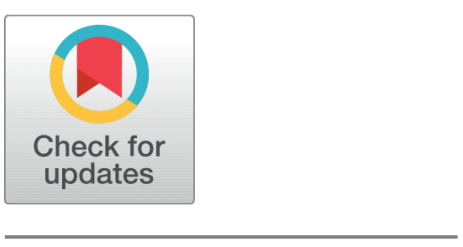

OPEN ACCESS

Received: 09-04-2020

Accepted: 28-04-2020

Published: 15-06-2020

Editor: Dr. Natarajan Gajendran

Citation: Memon S, Shaikh RA, Rind QB, Solangi $G H$, Jokhio SA, Ahmed M (2020) Hidden cable fault and remote locator by using Arduino. Indian Journal of Science and Technology 13(18): 1811-1820. https://doi.org/ 10.17485/JJST/v13i18.99

* Corresponding author. Sanaullah Memon

Department of Information Technology, Shaheed Benazir Bhutto University, Shaheed Benazirabad, Sindh, Pakistan. Tel.: +92-303-3468053

sanaullahmemon13@gmail.com

Funding: None

Competing Interests: None

Copyright: (c) 2020 Memon, Shaikh, Rind, Solangi, Jokhio, Ahmed. This is an open access article distributed under the terms of the Creative Commons Attribution License, which permits unrestricted use, distribution, and reproduction in any medium, provided the original author and source are credited.

Published By Indian Society for Education and Environment (iSee)

\section{Hidden cable fault and remote locator by using Arduino}

\author{
Sanaullah Memon ${ }^{1}$, Riaz Ahmed Shaikh², Qadir Bux Rind ${ }^{2}$, \\ Ghulam Hussain Solangi ${ }^{3}$, Shakeel Ahmed Jokhio ${ }^{4}$, Maaz Ahmed ${ }^{5}$ \\ 1 Department of Information Technology, Shaheed Benazir Bhutto University, Shaheed \\ Benazirabad, Sindh, Pakistan. Tel.: +92-303-3468053 \\ 2 Department of Computer Science, Shah Abdul Latif University, Khairpur, Sindh, Pakistan \\ 3 Department of Computing, Indus University Karachi, Sindh, Pakistan \\ 4 Department of Computer Science, Bahria University Karachi, Sindh, Pakistan \\ 5 Department of Computing, Indus University Karachi, Sindh, Pakistan
}

\section{Abstract}

Objectives: To device a method to locate the hidden cable fault. Methodology: The system makes use of an Arduino circuit and a supply of rectified electricity. Creation of the fault is made via the collection of switches. The relays are operated by integrated circuit relay driver. A $16 * 2$ LCD panel connected to the Arduino board to display the information. Findings: Using an Arduino module, the device is used to find the fault spot within kilometers in a hidden cable from the base station to the precise location. If the fault happens in an underground cable, it is difficult to locate the precise location of the defect for the purpose of fixing the specific cable. With respect to its form, we will be able to identify the fault and then the location would be traced after the project is implemented.

Keywords: Cable; Fault; Location; Underground; Arduino; Display; Relay; Diode; LCD; LED; Capacitor; Resistor

\section{Introduction}

The precise location of the fault in crowded areas or similar cities can be easily determined by an aloft line. Underground cables, rather than aloft ones, are commonly used in urban areas. Many electric, telephone, and other underground signal cables are available. Because of lack of knowledge of the precise location of the cable fault in the underground system, finding a fault can also take several hours or more. That will lead not only in a loss of personal and natural resources ${ }^{(1)}$, but also in serious economic harm such as industrial coincidences, financial networks, airport management structures and rail transport networks. It can relay a lot of discomfort to our daily lives. This study deals with Arduino board and LCD and is intended to assess the distance of kilometer-long hidden cable failure from base station.

The suggested solution is to use the standard Ohms voltage divider rule to figure out the precise position of the underground fault network. It saves a lot of time and works effectively. Recognition of type of cable fault has been widely researched. There are numerous forms of fault detection methods ${ }^{(2)}$ such as wavelet analysis, artificial 
neural network, particle swarm optimization (PSO) etc. The fault that occurs at a given distance is seen on an LCD interfaced with the Arduino board and the corresponding operation.

\subsection{Types of cable fault}

\subsubsection{Short circuit fault}

When electrical interaction happens due to insulation failure, a multi core cable with two or three conductors is considered a short circuit fault. Megger can also be used to check this error ${ }^{(3)}$. Figure 1 shows the short circuit fault.

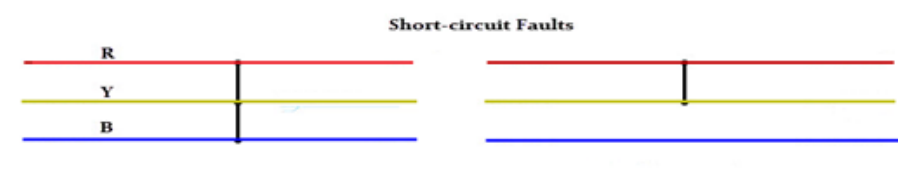

(a). Three-phase

(b) Phase-to-phase

Fig 1. Short circuit fault

\subsubsection{Open circuit fault}

If a cable conductor splits, it is called open circuit fault. For this particular reason the three conductors ${ }^{(4)}$ of three principal cables at extreme end are short tied and earthed. Figure 2 represents Open Circuit Fault.

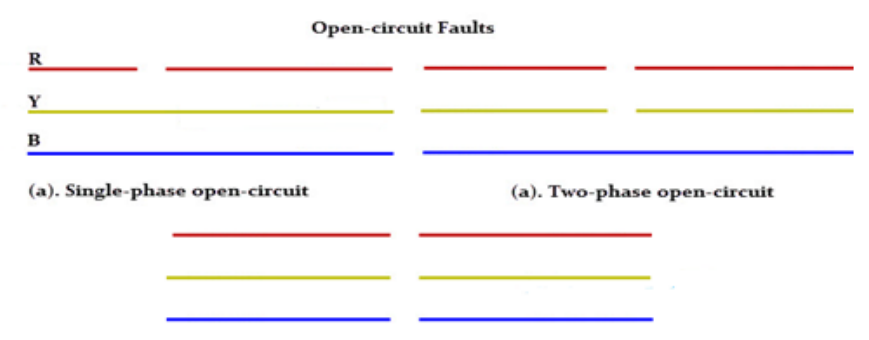

(a). Three-phase open-circuit

Fig 2. Open circuit fault

\subsubsection{Earth fault}

If a cable damaged conductor comes in contact with the surface, such a fault is known as terrestrial fault or ground fault. This kind of fault can be identified ${ }^{(5)}$ by connecting one terminal of the meggar to the conductor with another terminal and that in turn is connected to the Earth. Figure 3 shows the Earth fault of cables. 


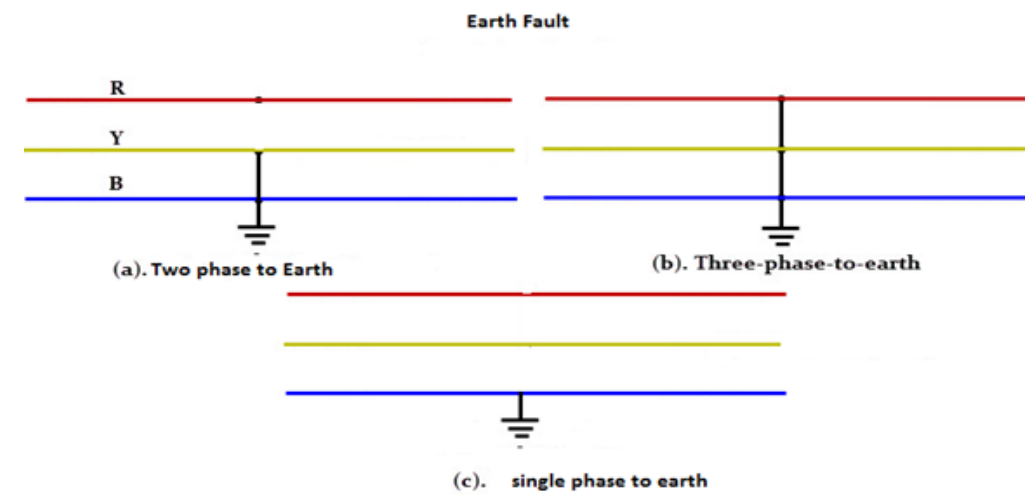

Fig 3. Earth fault

\section{Problem Statement}

Nowadays in Pakistan, most often the cabling network is underground, if any fault comes to exist in underground cable system (such as Telephone cable system, Power cable system or some other transmission system) then it is very difficult to locate the exact location of the fault. Time domain reflectometer and cable fault tracer were widely used by the experts to find exact location of fault. It is more time-consuming and cost effective in some ways. The experts and skilled people should be able to figure out the precise location and distance of fault in the underground copper network after the project has been implemented.

\section{Aims and Objectives}

The aim of the project is to determine the gap within kilometers between the underground cable and the base station so that human effort can be minimized and the technical staff can be encouraged to quickly identify the fault so that they can save their time and the other resources.

After this project has been completed we will be able to:

- Assess the gap between underground copper cables.

- Fault position in underground cabling infrastructures.

- Reducing the use of cost, manpower and other resources.

\section{Classification of the existing system for locating faults}

Fault location methods may be divided into two simple categories as seen in Figure 4, travelling wave based approach and impedance based measurement approach.

\subsection{Travelling Wave based method}

Travelling wave based method used to inject a certain wave from the location of the locator or to analyze the transients produced by the occurrence of the fault. In 1951, Lewis categorized travelling wave based schemes into separate four types A, B, C and D by using the moving voltage waves according to their modes of operation.

\subsection{Impedance measurement based fault locators}

Impedance measurement based fault locators offer an alternative to the question of fault position. Figure 5 displays the one line diagram of a three phase double in feed-fault transmission cable. Impedance measurement schemes are defined as being based on data from one or two ends of line. In phase $\mathrm{A}$, a line to ground fault exists at point $\mathrm{F}$ at a distance $\mathrm{x}$ from the locator with an RF resistance. The fault current IF consists of two elements IFs and IFr that flow from the ends of the transmitting and receiving 


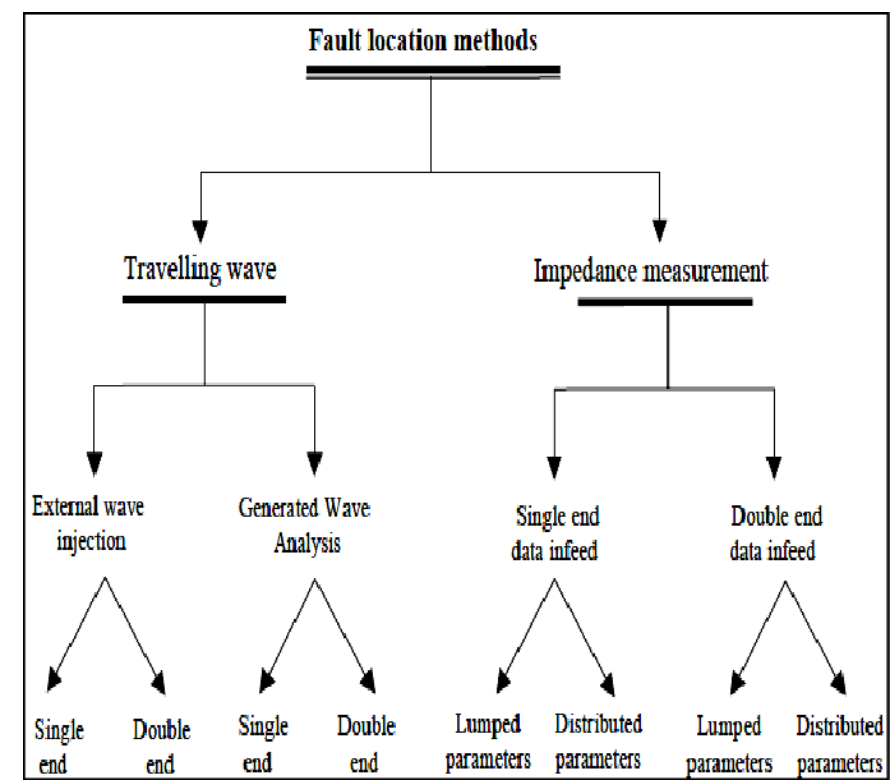

Fig 4. Classifications of fault location methods

respectively. The algorithm critical role is to approximate the gap of error $\mathrm{x}$ by using the receiving single end measurements or both end measurements as a feature of the complete line impedance $\mathrm{ZL}$, respectively.

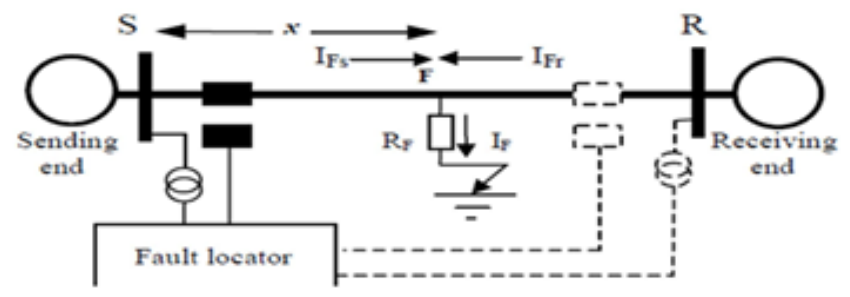

Fig 5. One line diagram of a faulted transmission line

\section{Project design methodology and tools}

The effectiveness of detecting fault and finding an underground cable depends primarily on the skills, expertise and experience. While cable tracing may be a complicated task, when more underground plant is built, it will very likely get much more difficult. The design methodology of project is supposed to be experimental as shown in Figure 6.

With reference to the flow chart, turn on all the operated equipment like Relay, LCD and Arduino board. If the fault occurs during operating the devices, then it is more important to find the location of fault. Read the fault and display the corresponding phase and distance measure of the fault location.

\subsection{Arduino}

An authoritative single board device, a fragile hardware source network that enables the development of electronic devices that operate together. It includes Arduino module, collection of various analog and digital I/O connectors, including USB on certain versions for the storage of personal computer programs ${ }^{(3)}$. 


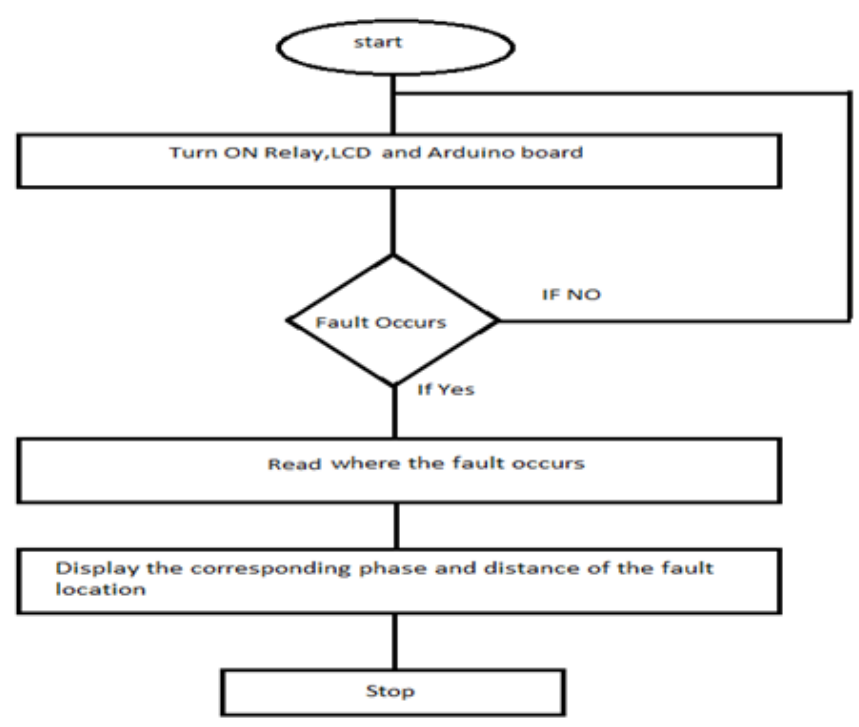

Fig 6. Flow chart of the project

\subsection{Arduino mega}

It has plenty (54!) of electrical input/output pins (14 can be used as PWM outputs), 16 analog inputs, a USB interface, a power jack, and a reset button. It provides anything you need to support the micro controller; simply connect it to an AC to DC adapter with a USB card or power it.

\subsection{Diode}

A diode is a device that enables current to flow uni-directionally only if worked below a defined voltage range. A diode only prevents the current in the opposite direction, as the opposite voltage cracks through the normally reverse barrier within a small range and the voltage at which this breakdown happens is called reverse breakdown voltage. Some diodes are constructed from components such as silicon, germanium, or selenium. Many diodes consist of metal electrodes in a cavity that has been evacuated or packed with a flat low pressure mineral gas. Figure 7 shows the symbol of diode.

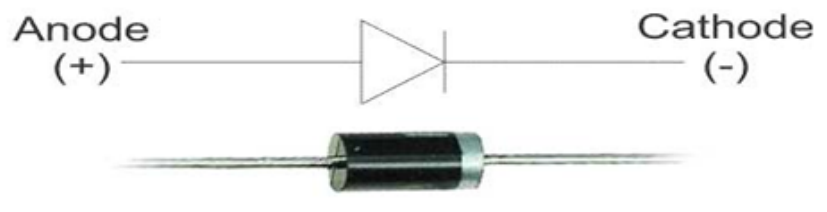

Fig 7. Symbol of diode

\subsection{LCD}

They are interfacing to microcontroller ATMEGA328P. We are consuming $16^{\star} 2$ liquid crystal displays as shown in Figure 8. Here $16^{\star} 2$ represents 16 rows and 2 columns ${ }^{(6)}$.

\subsection{Relay}

This is a controlled device that implicitly regulates an electrical circuit, which is governed through a modification in same or other electrical circuit. Relay is also known as sensing device that detects the fault and sends a travel signal to the circuit breaker to split the affected section ${ }^{(7)}$. 


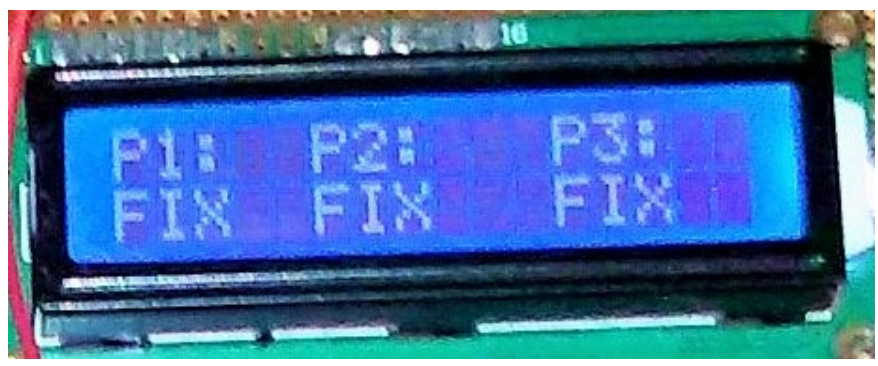

Fig 8. LCD (Liquid Crystal Display)

\subsection{Light emitting diode (LED}

A semiconductor chip which absorbs visible light via an electric current. The light is not inherently pure, but is monochromatic at a specific wavelength in most LEDs. An output of LEDs will vary from red to blue-violet. Few LEDs produce energy from Infrared (IR); such a structure is classified as IREDs.

\subsection{Voltage regulator}

An electrical regulator built to continuously preserve a steady amount of voltage. We need $5 \mathrm{~V}$ and $12 \mathrm{~V}$ power supply to complete this project. To get these voltage levels, voltage regulators 7805 and 7812 need to be used. The first number 78 reflects a positive supply and the 05 or 12 numbers show the voltage output levels required ${ }^{(8)}$.

\subsection{Transformer}

It transfers electrical energy from one circuit to another as per power shift or current missing frequency variation. In this phase step down transformer is used as shown in Figure 9. Usually, DC voltages are critical to the operation of different electronic devices which cannot be directly accomplished. The AC input accessible at the main source i.e., $230 \mathrm{~V}$ is to be held, thus owns the appropriate voltage point. The transformer theory is built to render ${ }^{(9)}$ faraday's electromagnetic induction laws.

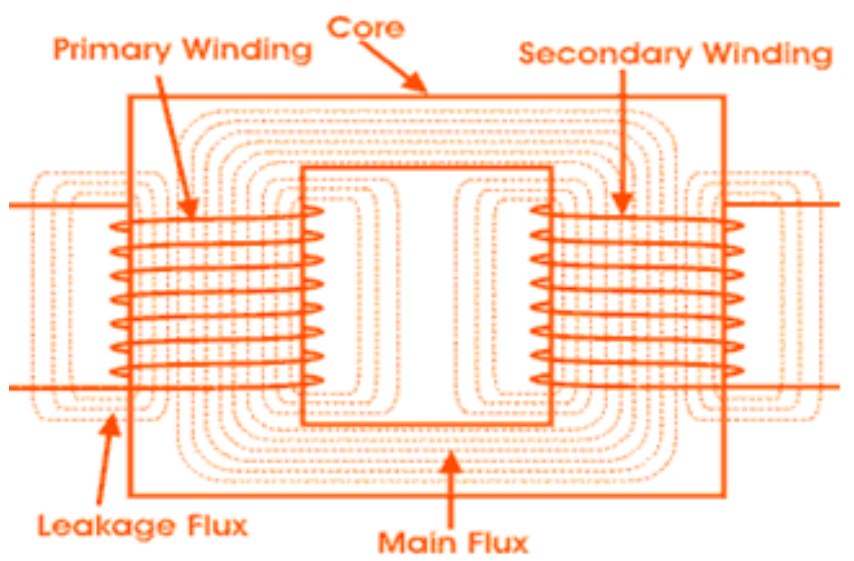

Fig 9. Main parts of transformer

\subsection{Micro controller}

It is said to be one chip true microcomputer. Most popular microcontrollers produced in the world market is Atmel atmega328p (Arduino), it is known for its reliability. Hardware is controlled by a single chip microcontroller. In this, time is inversely proportional to the speed means smaller access time and speed will be high ${ }^{(10)}$. 


\subsection{Rectifier}

It alters AC into pulsating DC signal. The output of transformer is fed to rectifier. It will be half wave or full wave rectifier. A bridge is used in this project for its merit, is keen on good constancy and full wave rectification. The present voltage AC is pointed to the diagonally opposite ends of the bridge. The load resistor is attached to the two other ends of the bridge.

\subsection{Slide switch}

The mechanical switches that are identified by their operating process. There is a slider in this switch, that shifts (slides) linearly from position to position making it simple to ON/OFF circuit with a fingertip. Slide switch has a rectangular covering with a bar handle that moves from one place to another and switches its state.

\subsection{Resistor}

An electrical part restricting or regulating the flow of electrical current in an electronic circuit. Resistors may often be used to supply an active unit such as a resistor with a particular voltage. All other considerations being equivalent, the current through the resistor in a direct current (DC) circuit is inversely proportional to its resistance, and directly proportional to the voltage across it.

\subsection{Capacitor}

Capacitor is a component that stores electric charges. A capacitor consists of two metal surfaces divided by a non-conductive or dielectric layer. Take a peek at the Figure 10 given below to read about dielectrics in a condenser. When voltage is passed over the two tiles, they generate an electric field. Positive charge is deposited on one plate and negative charge is accumulated on the other.

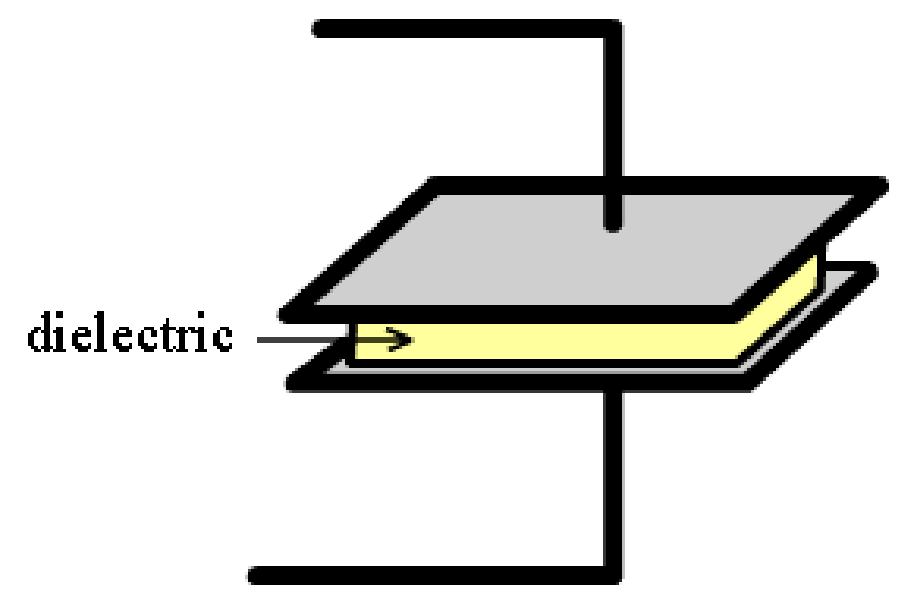

Fig 10. Working of Capacitor

\section{Results and Discussion}

\subsection{Proposed System}

Underground detector of fault system is used to locate an exact position of fault from the base station itself. Cables have only a few resistors. We focus primarily on the resistance. Resistance can differ according to the length of the cable. When the cable length is increased, the resistance value will also increase. If there are variances in the magnitude of resistance, we must call the fault point and locate the position by Arduino board technology. The fault point is representing the distance norm (kilometer) from the base station. This value is represented by unit of display. 


\subsection{Working of the Project}

Consumer voltage was used in the households and domestic purposes is $220 \mathrm{~V}$. This voltage is in step-down through step down transformer. In general, transformers are used in electric power applications to increase or decrease the voltages of alternating current. This step-down voltage is for device rectifier.

Rectifier is nothing but an electronic system that used to transform a supply of AC into DC. We have used bridge rectifier $12 \mathrm{~V} \mathrm{AC}$ in this project to convert supply to $12 \mathrm{~V}$ DC supply. Such voltages pass into the controller panel. Regulator is an electrical device used for the control of a constant voltage called voltage regulator 7805 . The 7805 voltage regulator maintains the 5V DC supply. Such voltages are enough for the relay unit to work and are used to manage the Arduino module.

Underground cable programs are added to Arduino super module to detect faults. If a fault occurs in the underground cables, the Arduino controller board will figure out the faults. The LCD shows the faults in Kilometer. In this project we manually build faults. There are several types of cables. Every cable possesses specific resistance depending on the material being used. The value of the resistance is proportional to the duration of the cable. Resistance is the project's lead role here. If some exception to the resistance happens, then that specific point is called FAULT, it would change the voltage value.

Arduino is the advanced embedded device version. These Arduino have several different forms, but we choose Arduino Mega, it can be used to build user friendly environment. Using serial port, it is easily used to implement other devices. Relay is nothing but electrical devices here that if any fault occurs in the line, function as a switch, will disconnect the line with the relay. The relay connector shifts from usually near conduct to regular open conduct. Location of the fault and break in the line of a fault can be detected quickly. The control device attaches to and shows the Arduino module that is used to where the fault occurs. Following Figure 11 shows the project circuit diagram.

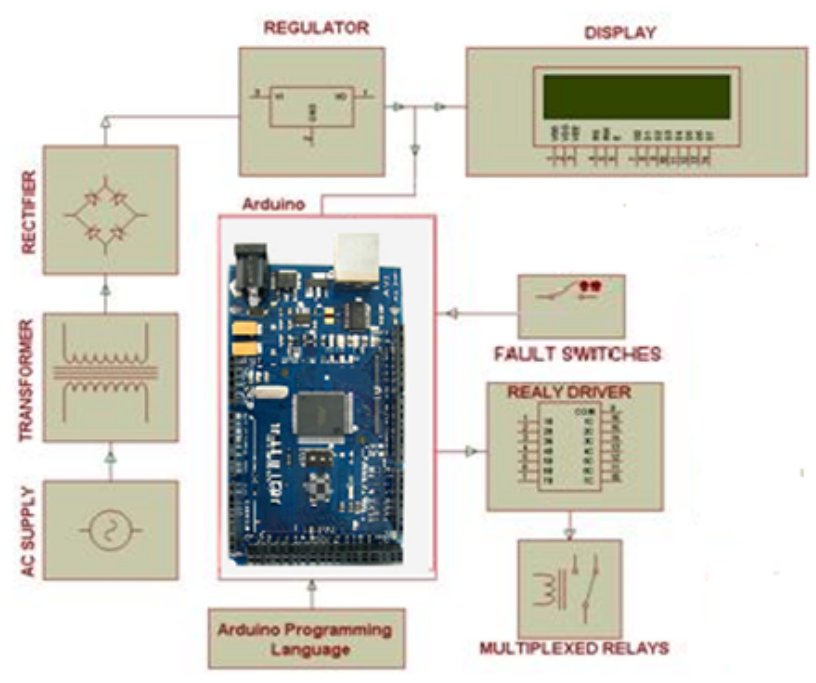

Fig 11. Circuit diagram of project

The fault occurs in any single phase (like P1, P2, P3) as shown Figure 12. Fault clearly occurs in P2 and distance of fault location is exactly $2 \mathrm{~km}$ and when fault occurs pertaining to the relay of phase 2 , it switches off and the rest of phases will work normally.

In Figure 13, the faults occur in two phases and the result of related relay P1 and P2 is off due to fault and LCD display. The fault location like in $\mathrm{P} 1$ at $3 \mathrm{~km}$ and in $\mathrm{P} 2$ at $2 \mathrm{~km}$ and the third phase works normally.

In Figure 14, the fault occurs in phases 1,2 and 3, each phase is related to a relay and LED as indicator so here all relays are off as well as led.

When fault occurs in multiple phases in different locations like in $1 \mathrm{~km}, 2 \mathrm{~km}$ and so on. It cannot be repaired and remains the same until the repairs are done at the first location as shown in Figure 15. 


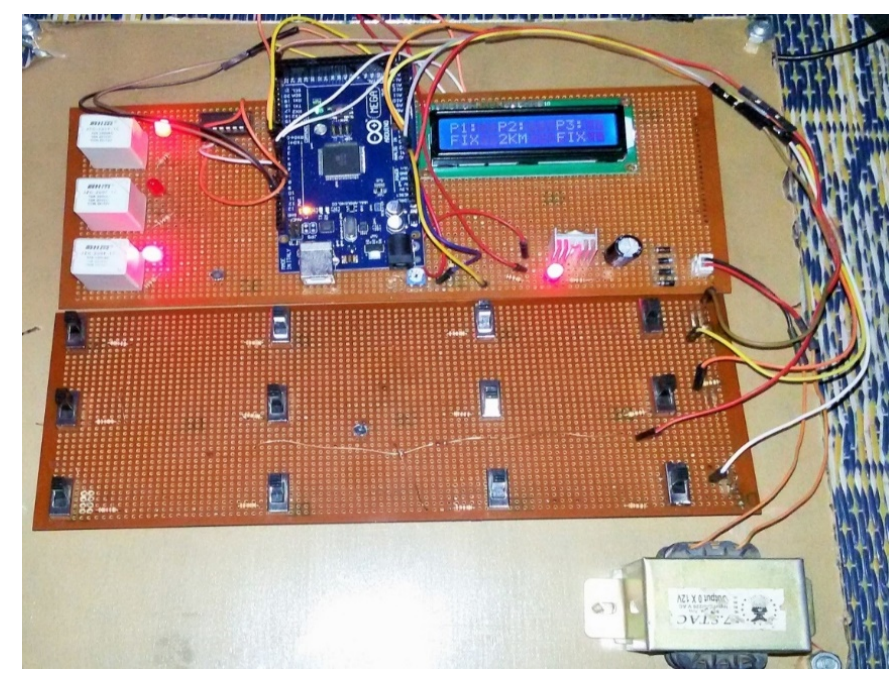

Fig 12. Fault occurs in single phase

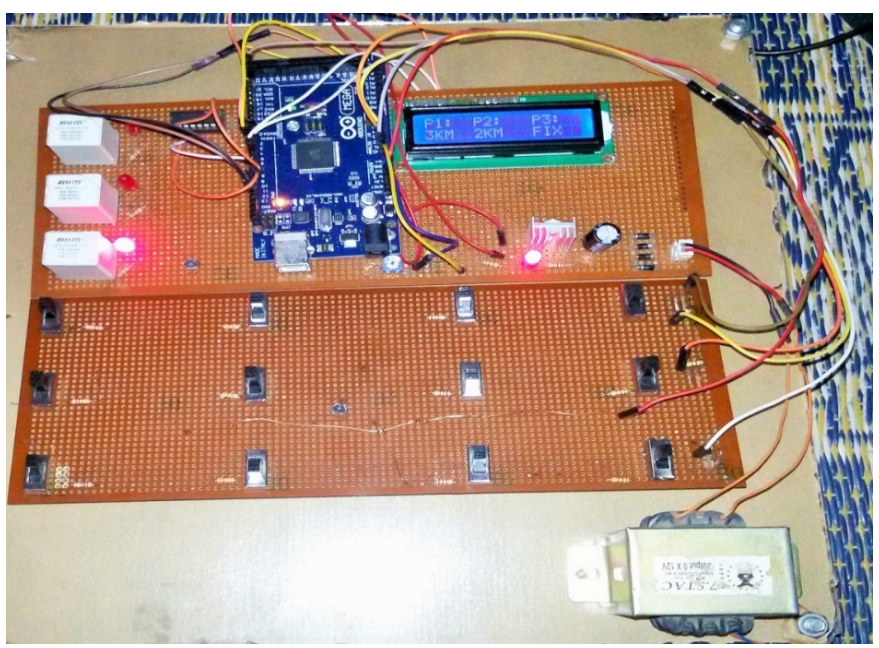

Fig 13. Fault occurs in two phases

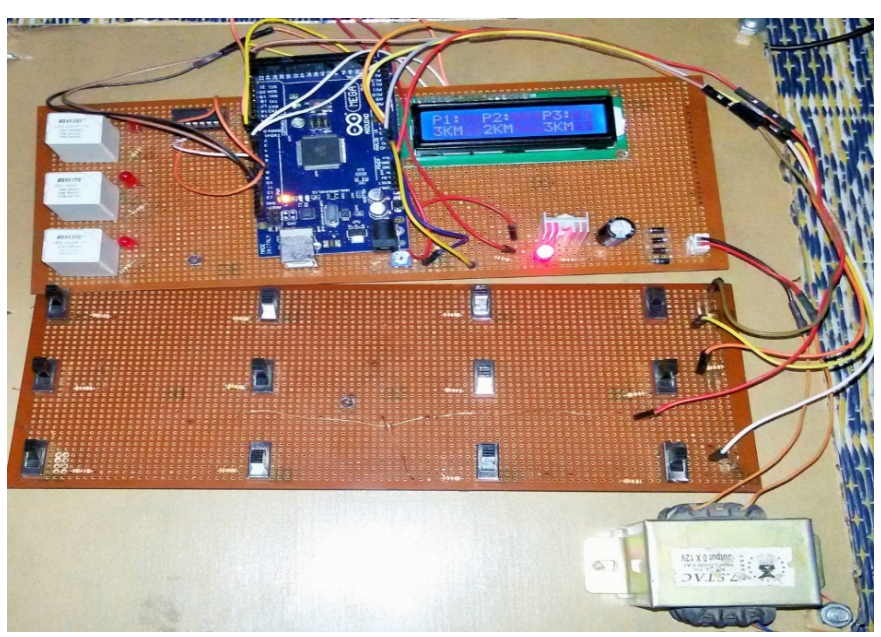

Fig 14. Fault occurs in three phases 


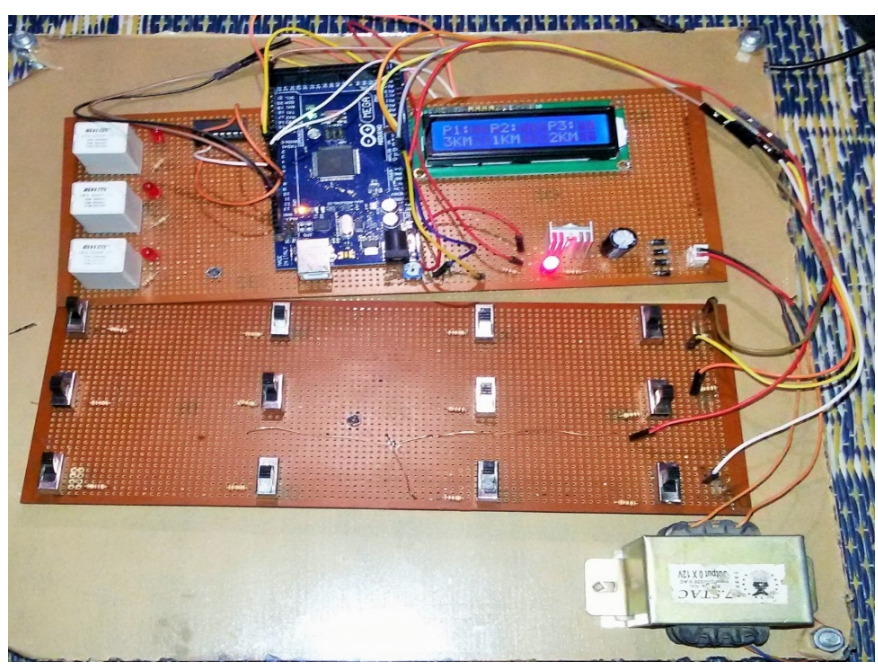

Fig 15. Fault occurs in multiple locations

\section{Conclusion}

Identifying faults in underground cables is not an easy work to do, but use of techniques involving Arduino board can determine the exact fault location easily. In the proposed system, when faults are produced in the cable, the display device indicates the exact position of the fault and fault length. By this project, the fault can be located within the range of $1 \mathrm{~km}$ and so on. Hence, the exact location of the fault can easily be found.

\section{References}

1) Wang M, Stathaki T. Online fault recognition of electric power cable in coal mine based on the minimum risk neural network. Journal of Coal Science and Engineering (China) . 2008;14(3):492-496. Available from: https://link.springer.com/article/10.1007/s12404-008-0106-1.

2) Asanga R, Halgamuge SK, Halgamuge HC. Self-organizing hierarchical particle swarm optimizer with time-varying acceleration coefficients. IEEE Transactions on evolutionary computation. 204;8(3):240-255. Available from: https://ieeexplore.ieee.org/document/1304846.

3) Bascom EC, Dollen DWV, Ng HW, IEEE. Computerized underground cable fault location expertise. In: and others, editor. Proceedings of IEEE/PES Transmission and Distribution Conference. 1994. Available from: https://ieeexplore.ieee.org/document/328403.

4) Densley J. Ageing mechanisms and diagnostics for power cables-an overview. IEEE electrical insulation. 2001;17(1):14-22. doi:https://ieeexplore.ieee.org/document/901613.

5) Fakhrul MI, Oo MTA, Azad SA, IEEE. Locating underground cable faults: a review and guideline for new development. In: and others, editor. 22nd Australasian Universities Power Engineering Conference (AUPEC). 2012. Available from: https://ieeexplore.ieee.org/document/6360223.

6) Dharani D, Sowmya T. Development of a Prototype of Underground Cable Fault Detector. International Journal Electrical, Electronics, and Computer Systems . 2014;2. Available from: http://www.irdindia.in/journal_ijeecs/pdf/vol2_iss7.

7) Singh A, Ansari MA. Under Ground Cable Fault Detection using IOT. Advanced Research in Electrical and Electronic Engineering;4(1). Available from: http://www.ijareeie.com/volume-4-issue- 1 .

8) Nichal A, Bhosale MS, Shirsavade MV, Jadhav MY. IOT Based Underground Wire Fault Detection Technique. International Journal of Innovative Research in Electrical, Electronics, Instrumentation and Control Engineering. 2016;4(4):1-4. Available from: https://www.ijireeice.com/upload/2016/april16/IJIREEICE\%2031.pdf.

9) Dhekale PM, Bhise SS, Deokate NR. Underground Cable Fault Distance Locator. International Journal of Innovations in Engineering Research and Technology. 2015;2(4):1-7. Available from: https://www.ijiert.org/admin/papers/1429469524_Volume\%202\%20Issue4.pdf.

10) Lee, Duck-Su, Yang X, Choi MS. A line to ground fault location algorithm for underground cable system. The Transactions of the Korean Institute of Electrical Engineers. 2005;54(6):267-273. Available from: http://www.koreascience.or.kr/article/JAKO200502637246315.page. 